\title{
TRANSFORMAÇÕES CONTEMPORÂNEAS E POLÍTICA EDUCACIONAL NO BRASIL: FORMAÇÃO PROFISSIONAL EM SERVIÇO SOCIAL NA EXPERIÊNCIA DO IFCE
}

\section{TRANSFORMATIONS CONTEMPORARY AND EDUCATIONAL POLICY IN BRAZIL: VOCATIONAL TRAINING IN SOCIAL WORK IN IFCE EXPERIENCE.}

\author{
Evelyne Medeiros Pereira ${ }^{1}$ \\ Cynthia Studart Albuquerque ${ }^{2}$
}

\begin{abstract}
RESUMO
Este artigo é fruto da realização de duas pesquisas que tiveram como objetivo analisar a experiência do Curso de Serviço Social no Instituto Federal de Educação, Ciência e Tecnologia do Ceará (IFCE) em meio as transformações contemporâneas, particularmente da realidade brasileira, e seus reflexos sobre a política de educação superior. Esta, sendo atravessada pela contradição entre acesso e precarização, adensa os desafios postos para a formação profissional em Serviço Social e a construção de estratégias coletivas que venham a garantir conquistas não apenas para a profissão, mas para o conjunto da classe trabalhadora.
\end{abstract}

Palavras-chave: Educação. Formação Profissional - Serviço Social - Institutos Federais (IF's).

\begin{abstract}
This article is the result of two studies that aimed to analyze the experience of the Social Work course at the Federal Institute of Education, Science and Technology of Ceará (IFCE) among the contemporary transformations, mostly about the reality of Brazil, and its impact on higher education policy. A reality that is traversed by the contradiction between access and precariousness, which thickens the challenges posed to the vocational formation in Social Work and the construction of collective strategies that will ensure achievements not only to the profession but also for the whole working class.
\end{abstract}

Key-words: Education. Professional qualification - Social Work - Federal Institutes (IF's). 


\section{INTRODUÇÃO}

O Serviço Social no Brasil apresenta particularidades históricas que têm constituído a sua cultura profissional, em permanente relação com as transformações societárias que acompanham e interferem continuamente na trajetória da profissão. Mesmo tendo alcançado passos largos na sua legitimidade, em seu projeto e estatuto profissional, a marca do conservadorismo tão presente na gênese da profissão, ainda perdura utilizando-se de "novos" artefatos. Como expressão desse

processo, destacam-se: a prática tecnicista, pretensamente neutra, meramente assistencial, imediatista e filantrópica; e a dificuldade de romper com a "lógica do passado" que caracteriza o Serviço Social no âmbito estrito da execução terminal das políticas sociais mediante a uma formação técnica especializada para a prática da assistência e manutenção do status quo.

Esse processo, vale lembrar, não pode ser compreendido à parte de um conjunto de transformações que configuram a realidade contemporânea. Esta, marcada pela crise capitalista e pelo avanço do processo de financeirização da economia, vem apresentando diversos desdobramentos em escala global que suscitam novas exigências às práticas profissionais, aos processos de formação profissional e à organização das categorias de trabalhadores, em particular, de assistentes sociais. Novas determinações sobre o Serviço Social nos desafiam a refletir sobre o processo educativo e formativo com cuidadosa avaliação crítica acerca do significado da profissão na divisão sociotécnica do trabalho, os seus vínculos com o real e a opção política que os sujeitos profissionais imprimem ao projeto profissional e societário.

\section{CONJUNTURA BRASILEIRA, EDUCAÇÃO E SERVIÇO SOCIAL HOJE}

O novo padrão de sociabilidade impõe outra maneira de trabalhar, viver e pensar, em que se fortalece e reproduz, ao máximo, valores fundamentais para a reprodução ampliada de capital, tais como o individualismo, a competitividade, o hedonismo, a indiferença à barbarização da vida social. O mercado de trabalho passa a requerer um trabalhador polivalente com novas características técnicas e sociointelectivas capaz de ocupar diferentes funções e postos de trabalho. Nessa perspectiva, torna-se necessário formar novos perfis profissionais que imprimam renovados atributos, ideias e valores à força de trabalho, configurando no indivíduo trabalhador um perfil profissional com ênfase na criatividade, no empreendedorismo, na adaptabilidade e com pouca capacidade reflexiva e organizativa.

O processo de formação profissional em Serviço Social assume, nesse contexto, enormes desafios, no sentido de garantir um perfil profissional em consonância com o projeto profissional construído historicamente pela categoria profissional, orientado pelo Código de Ética/1993, a Lei de 
Regulamentação da Profissão (n 8.662/1993) e as Diretrizes Curriculares da Associação Brasileira de Ensino e Pesquisa em Serviço Social (ABEPSS). Esse projeto defende um perfil em que o profissional tenha renovada capacidade intelectiva, técnica, ético-política e organizativa ao definir uma formação voltada para o conhecimento e a transformação da realidade. Concepção oposta ao entendimento presente nos requisitos do mercado em que competências são entendidas como “capacidades de realizar tarefas práticas, desvalorizando e mesmo declarando desnecessário o conhecimento científico" (KUENZER apud KOIKE, 2009, p.13).

Mesmo diante de um cenário com inúmeras adversidades, o projeto de formação profissional constitui-se orientado pela teoria social crítica, tendo como condição geral a articulação entre as dimensões investigativa e interventiva, além de princípios como a unidade teoria e prática, o pluralismo, a interdisciplinaridade e a indissociabilidade entre ensino, pesquisa e extensão, entre estágio e supervisão acadêmica/profissional, sendo a ética um princípio formativo que deve atravessar todo o desdobramento curricular. Esse processo permitiu, entre avanços e recuos, que o Serviço Social no Brasil venha "se constituindo, também, numa área do conhecimento" (MOTA, 2013, p.18).

Dirigindo nossa atenção para a realidade mais recente do país, é possível observar alguns aspectos que nos impedem de desenvolver uma análise linear e mecanicista da realidade e suas contradições. Estas entendidas sob ângulos distintos que, de um lado, apontam para a retomada do crescimento econômico e de mudanças nas condições de vida da população mais subalternizada nos anos 2000; de outro, como uma "nova fase de desenvolvimento capitalista" que terá como uma de suas principais marcas o retorno da "ideologia desenvolvimentista" (CASTELO, 2012, p.614). Para Boito Jr (2012, p.07), a última década foi caracterizada por um contexto em que a correlação de forças políticas favoreceu a formação de uma "frente neodesenvolvimentista", gelatinosa e heterodoxa, que viabilizou governos de "composição de classes" em torno de um projeto de desenvolvimento possível nos marcos do modelo neoliberal.

Nessa perspectiva, tomando como base as análises de Alves (2013, s/p), podemos entender que, embora "o projeto burguês do neodesenvolvimentismo" tenha nascido "no bojo da crise do neoliberalismo (...), ele não poderia ser mera continuidade do projeto I (projeto neoliberal), oriundo da década de 1990, sob pena de ir à ruína”. Observamos, porém, que o período de retomada do papel do Estado em impulsionar o crescimento econômico no país com o discurso de um novo desenvolvimento, dá sinais de esgotamento, especialmente a partir de um conjunto de ações que conformam o ajuste fiscal em curso no país, penalizando os trabalhadores pelos efeitos da crise. Isto em meio à expansão da especulação e do capital financeiro em esfera mundial, a manutenção de uma política monetária e cambial conservadora com taxas de juros elevadas, controle inflacionário e garantia do superávit primário. 
Esse processo contraditório, no âmbito da educação, possibilitou a conformação de um pêndulo entre a ampliação no acesso e a precarização das condições de acesso. Esse contexto (re)põe dilemas à profissão, expressos em seus mais diversos espaços de debates e deliberações.

No estado do Ceará, conforme dados do Conselho Regional de Serviço Social, $3^{\text {a }}$ região (CRESS, 2014), em seis anos ocorreu uma expansão considerável da oferta de curso de graduação em Serviço Social, especialmente na esfera privada, existindo hoje aproximadamente 26 instituições de ensino superior oferecendo o curso. Destas somente a Universidade Estadual do Ceará (UECE) e o Instituto Federal de Educação, Ciência e Tecnologia do Ceará (IFCE) ofertam cursos públicos, presenciais e gratuitos, os demais são implementados pela iniciativa privada, sendo 07 na modalidade à distância, criados a partir de 2005 em mais de 60 cidades do interior do Ceará. Esse quadro fomentou a ampliação em mais de $600 \%$ no número de bacharéis em Serviço Social com registro profissional no CRESS/CE, advindos principalmente da esfera privada nas modalidades presencial e à distância. Em 2013, por exemplo, a quantidade de profissionais formados no estado pela $\mathrm{EaD}$ era de $45,5 \%$, já aqueles formados pelo ensino privado presencial correspondia a 40,9\%, sendo apenas $11,2 \%$ dos inscritos advindos do ensino público presencial.

Essa expansão, se por um lado passa a ser identificada como acesso ao ensino superior, por outro, é acompanhada pelo adensamento dos diversos problemas e dificuldades no cotidiano do exercício e da formação profissional dos assistentes sociais, a exemplo do aligeiramento dos conteúdos e do rebaixamento acadêmico que tendencialmente implica em um perfil profissional mais pragmático, apresentando profundas divergências e ameaças ao projeto ético-político da profissão.

A educação, nesse contexto, sofre em 2015 um corte de cerca de 9,5 bilhões no orçamento destinado ao Ministério da Educação (MEC). Diante da atual correlação de forças desfavorável no período de crise econômica e, sobretudo, política, setores dominantes na sociedade brasileira intensificam iniciativas que potencializam tanto os níveis de lucratividade com a mercantilização da educação como a capacidade de educar as classes e suas frações dentro de uma visão de mundo capitalista. Como expressão desse processo, Leher (2015) nos apresenta o exemplo das recentes fusões entre grandes grupos educacionais, como Kroton e Anhanguera, e a criação de movimentos como o Todos pela Educação. O primordial é a busca de superlucros por meio de fundos de investimentos e a defesa de um projeto de educação em que a classe dominante defina a forma e o conteúdo do processo formativo das crianças e jovens no país.

Em meio a tais circunstâncias, atentando para as particularidades regionais, chamamos a atenção para a importância que assumem os Institutos Federais (IF's), particularmente na realidade cearense, passando de 5, até 2002, a 25 unidades, atualmente. Nesse contexto, é criado, em 2010, o Curso de Serviço Social no IFCE, campus Iguatu, que em 2015 foi reconhecido pelo MEC, 
configurando-se como o segundo curso presencial público do estado, sendo o primeiro oferecido pela UECE, com mais de 60 anos de criação, e o único em Serviço Social criado na Rede Federal de Educação Profissional e Tecnológica no Brasil.

Nesse sentido, estamos tratando do primeiro curso em Serviço Social público do interior cearense, mais precisamente na região Centro-sul do estado, onde nos últimos anos têm se proliferado graduações nessa área, em geral, sem nenhum parâmetro de qualidade, especialmente na modalidade à distância, por intermédio de instituições privadas. Assim, desde sua criação, o Curso vem enfrentando o desafio de se consolidar na região e no próprio IFCE, sofrendo constantemente os rebatimentos das contradições inerentes à política de expansão da educação superior dos últimos anos.

\section{FORMAÇÃO PROFISSIONAL EM SERVIÇO SOCIAL NO IFCE: trajetória e desafios}

Trata-se de um curso que possui duração de 4 anos, com 8 semestres letivos, e vem se conformando e ganhando notoriedade, ofertando semestralmente 35 vagas para o período noturno via "processo seletivo público e/ou a utilização da nota do Exame Nacional do Ensino Médio (ENEM) por meio do Sistema de Seleção Unificada (Sisu/MEC)". Isso além da oferta, em média, de 15 vagas semestrais via processo de seleção pública por edital para ingresso de transferidos e graduados (MEC, 2015).

O Projeto Político-pedagógico do Curso (PPC), reformulado em 2013, conforme Relatório de Avaliação do MEC (2015), está coerente com as "as diretrizes curriculares nacionais (CNE) e as orientações dos órgãos de regulamentação e representação em Serviço Social” (p.02).

De acordo com a atual coordenação do curso (2015), até o primeiro semestre de 2015 foram realizadas um total de 1.554 matrículas no curso de Serviço Social, tendo 24 alunos formados e 12 concludentes. Para o semestre de 2015.1, considerando o conjunto dos 8 semestres, os dados apontam que foram realizadas 232 matrículas, 05 evasões, 06 cancelamentos, 02 trancamentos, 01 transferência externa e 08 fechamentos de período.

A referida graduação, reconhecida pelo MEC em maio de 2015, obtendo como conceito final 4,0, de uma escala de 1,0 a 5,0, que corresponde a um perfil muito bom de qualidade, teve a formação da primeira turma ao final do ano de 2014. A matriz curricular é composta por 38 disciplinas obrigatórias e 6 optativas, sendo 3.610 horas/aula distribuídas em 2.840 horas de disciplinas obrigatórias e 160 horas de disciplinas eletivas. Isto além das 450 horas de estágio supervisionado e 160 horas de atividades complementares (IFCE, 2013). 
O estágio supervisionado "apresenta normatização/regulamentação [...]; há documentação organizada, supervisão acadêmica com no máximo 15 alunos por docente, visitas aos campos de estágio e outras ações". Existem atualmente cerca de 55 supervisores de campo cadastrados e por volta de 23 desempenhando tal atribuição no primeiro semestre de 2015. "Destaca-se que o curso propõe, de forma sistemática, capacitações aos supervisores de campo" (MEC, 2015, p.02). Dessa forma, as ações no âmbito do estágio são orientadas pela Política Nacional de Estágio (PNE) da ABEPSS, tal como demonstra o PPC (2013), tendo sido recentemente implantadas a Coordenação de Estágio Supervisionado em Serviço Social, em 2014, e a Comissão de Estágio, em 2015, que acompanham hoje os processos de inserção dos estudantes nos campos de estágio.

Em relação ao quadro docente, até o primeiro semestre de 2015 , consta oficialmente o número de 20 docentes vinculados ao curso. Destes, 13 da área específica de Serviço Social, sendo 08 docentes efetivos em regime integral (40h), 03 na condição de substituto (40h) e 02 temporários (40h). Isto diante do afastamento integral para qualificação (doutoramento) de 04 docentes da área específica. Os professores temporários representam demandas ainda existentes que deveriam ser ocupadas por professores efetivos. Em termos de titulação, todos os efetivos possuem mestrado, estando 06 em processo de doutoramento. Já aqueles das áreas afins, totalizam-se 07 divididos, segundo área de formação, da seguinte forma: 2 da área da Filosofia, sendo 1 efetivo e 1 substituto; 2 da Letras, sendo 2 efetivos; 2 da História, sendo 2 efetivos e 1 da Pedagogia, efetivo. Como podemos observar, ainda existe a demanda também de docentes das áreas afins, a exemplo das Ciências Sociais (ou Sociologia) e da Psicologia.

Outro aspecto relevante no processo de implantação da graduação foi a falta de professores, especialmente da área específica, e de corpo técnico de apoio direto e permanente ao curso implicou em muitas fragilidades do primeiro PPC. Daí a necessidade, logo percebida pelas primeiras docentes da área de Serviço Social, em realizar uma profunda reformulação curricular entre os anos de 2012 e 2013. No processo de revisão curricular, algumas instâncias coletivas foram fortalecidas, como o Colegiado do Curso, a Coordenação do Curso e o Núcleo Docente Estruturante (NDE). Além disso, viu-se a necessidade de estabelecer uma flexibilização do currículo, articulação da teoria com a realidade, a partir de uma teoria social crítica, compreendendo a realidade da própria profissão, como também a questão da interdisciplinaridade, pluralismo teórico, a ética na formação curricular.

Levando em consideração a condição de professor do Ensino Básico, Técnico e Tecnológico (EBTT), a verticalização do ensino e o fato do IFCE não está organizado em departamentos ou centros por área ou curso, sendo todos os professores, independente de suas áreas, vinculados a Diretoria de Ensino e ao Departamento de Ensino, atualmente, os docentes das áreas afins, em geral, perpassam outros níveis de ensino (integrado, subsequente e/ou superior), sendo o caso dos 
docentes em Serviço Social uma particularidade. Sobre isto, nos primeiros anos do curso, uma das principais motivações de contestação das docentes da área de Serviço Social junto à gestão do IFCE foi o fato de terem que lecionar disciplinas de Filosofia, Sociologia, Antropologia, entre outras, em cursos e modalidades distintas da área para qual as docentes prestaram o concurso (ou mesmo no próprio curso em disciplinas das áreas afins) que a formação em Serviço Social não é habilitada, conforme a Lei que regulamenta a profissão (Lei 8.662/93).

Fato esse também decorrente da falta de professores das áreas afins na instituição, especialmente de Sociologia e Filosofia, tornando mais suscetível as condições de trabalho à precarização e a polivalência, implicando, inclusive, no desenvolvimento de outras atividades, como pesquisa, extensão e apoio ao ensino. Daí a dificuldade também de tempo disponível para o planejamento, coordenação, acompanhamento e avaliação das ações no âmbito do curso, além da revisão curricular e elaboração de propostas de regimento interno para o Colegiado, entre outras propostas de alterações nas normativas e regulamentos internos exigidas com as mudanças institucionais e com a inserção de cursos com outros parâmetros de formação.

No entanto, embora a carga horária máxima oficialmente estabelecida ainda seja excessiva para a atividade de ensino, considerando que a atividade docente ainda agrega outras ações, as constantes reivindicações em âmbito nacional, estadual e local por parte dos servidores e estudantes tem impulsionado uma maior discussão no âmbito dos IF's e particularmente do IFCE sobre as mudanças ainda necessária a serem feitas, como aquelas relativas a carga horária e condições de trabalho e ensino. Assim, mesmo que parte das normativas e resoluções ainda estejam em revisão e discussão, atualmente existe no IFCE o estabelecimento de uma média em sala de aula de 16 horas semanais. Muitos cargos de coordenação foram regulamentados e gratificados, com carga horária específica, e, em certa medida, os colegiados foram devidamente estabelecidos e reconhecidos, muito embora ainda haja demanda por regulamentação.

A organização e reivindicação por parte das professoras e estudantes, muitas vezes causando estranhamento aos olhos dos demais servidores, tem notadamente contribuído para uma maior motivação da gestão institucional ao compromisso com o curso, atentando para suas particularidades. Sobre isso, sinalizamos a proximidade existente entre os docentes e discentes com as entidades representativas da categoria (Conjunto CFESS/CRESS, ABEPSS, ENESSO). Lembremos que a "articulação com os movimentos de outras categorias profissionais que partilhem dos princípios" do Código de ética da profissão "e com a luta geral dos trabalhadores" (BRASIL, 1993) é um dos princípios fundamentais que regem o Serviço Social.

Atualmente, todos os professores da área específica, bacharéis em Serviço Social, ministram aulas nas disciplinas específicas do curso com uma média de 16 horas em sala de aula, exceto aqueles que, em virtude de funções em coordenações e desenvolvimento de pesquisa, extensão e/ou 
acompanhamento de monitoria e demais orientações acadêmicas, lecionam um número menor de disciplinas, não podendo exceder a quantidade mínima estabelecida em sala de aula que é de 8 horas semanais, o que indica uma resposta institucional às demandas relativas a professor efetivo na área de Serviço Social, como também nas áreas afins, através de concursos e contratações.

Dentre as instâncias de acompanhamento pedagógico, discussões e/ou definições coletivas, a graduação possui um Núcleo Docente Estruturante (NDE), a Coordenação e o Colegiado do Curso, “instituído e regulamentado, com registro de reuniões em atas, bem como programação de encontros com o objetivo de acompanhar, monitorar e avaliar tanto as atividades do curso, quanto o processo de formação”.(MEC, 2015, p.02). Porém, com base na análise dos documentos internos do Colegiado e da Coordenação do curso, de início, podemos observar uma certa resistência por parte das instâncias da gestão em garantir e considerar as decisões coletivas do curso, atribuindo a este relativo estigma pelo fato da sua diferenciação aos demais que, até então, não questionavam os trâmites com que as decisões e ações eram tomadas e desenvolvidas na instituição.

Desde o primeiro ano de implantação da graduação (2011), os estudantes criaram o Centro Acadêmico de Serviço Social (CASS), com sala própria a partir de 2014, importante espaço de organização do Movimento Estudantil de Serviço Social (MESS), em articulação com outros movimentos sociais como o Levante Popular da Juventude, que se "apresenta como atuante às demandas do curso e há disponibilização de transporte e auxílio para eventos; há políticas de atenção ao aluno tanto pela implementação da Política Nacional de Assistência Estudantil, quanto por ações locais de acompanhamento" com a presença de 02 psicólogas, 02 assistentes sociais e 06 pedagogas (MEC, 2015, p.02). Segundo dados de 2014 do Departamento de Assistência Estudantil do campus, cerca de 87 alunos do curso são beneficiados com auxílio-moradia, auxílio-transporte, auxílio-óculos e auxílio-creche. Contudo, não há, no âmbito da assistência estudantil, estruturas como residência e restaurante universitário ou acadêmico para os estudantes do ensino superior, somente para o ensino médio integrado.

O perfil dos estudantes do curso, até 2014, era conformado, em geral, por jovens de 18 a 24 anos, solteiros e mulheres. Em torno de 45\%, até 2013, eram advindos de outras cidades, menores e, em geral, da mesma região do estado. Porém, o curso também tem atraído estudantes de regiões mais distantes, a exemplo de Fortaleza, em virtude de existir na capital apenas uma instituição pública que oferte o curso público e gratuito (UECE). Essa migração é acompanhada, em geral, por uma reconfiguração do cotidiano desses jovens que muitas vezes passam a morar sozinhos, em pensões ou repúblicas e a se deparar com uma nova realidade, acadêmica e política. As dificuldades que antes eram relacionadas somente ao acesso à educação superior pública, agora passam a ser de outras ordens. Os estudantes migrantes, em sua maioria com baixa condição socioeconômica e advindos da zona rural ou periférica das cidades, passam a se deparar com a necessidade de garantir 
a permanência no curso, o que implica em acesso à moradia, alimentação e transporte. Este passa a ser mais central na vida dos estudantes que moram e/ou trabalham em cidades vizinhas e necessitam se deslocar diariamente para Iguatu, uma cidade que ainda não possui uma infraestrutura adequada para essas novas demandas, a exemplo da falta de transporte público e coletivo na cidade.

Outro aspecto relevante da realidade local que implica diretamente nas condições de vida e estudo dos estudantes, são as elevadas taxas de aluguéis frente ao avanço da especulação imobiliária nas cidades médias. Daí a importância da política de assistência estudantil e do incentivo à pesquisa, à monitoria e à extensão através de auxílio específico e/ou bolsas acadêmicas, o que, conforme os próprios estudantes, não supre ao menos a metade dessas necessidades, tornando-se pautas constantes de reivindicação da categoria estudantil. Em boa parte dos casos, a procura por emprego, nas condições mais informais e precárias, passa a ser o caminho de muitos dos estudantes.

Diante dessa realidade, observamos que a maioria dos alunos advém de escolas públicas e trabalha e/ou possui algum tipo de renda mensal familiar, sendo de 1 a 2 salários-mínimos. Esse aspecto implica também na grande procura de cursos superiores noturnos, sendo a escolha pelo Serviço Social apresentada, em geral, como primeira opção. Dessa forma, a procura pelo curso tem oscilado a cada semestre, apresentando um aumento nos semestres mais recentes, o que pode advir de um maior conhecimento e referência da população sobre o curso.

Tais circunstancias refletem também no déficit de leitura e escrita e nos limites em acompanhar os conteúdos, considerados densos e com alta carga de leitura alta, por parte dos estudantes do curso em questão. Essa condição se adensa em uma realidade cada vez mais comum de conjugar os estudos a uma rotina de trabalho desgastante. Tal circunstância tem incidido diretamente no quadro de evasão, muito embora boa parte dos entrevistados cursem regularmente as disciplinas semestrais e tenham acesso a espaços como a biblioteca municipal e da instituição para o alcance de parte bibliografia utilizada, o que implica na demanda por uma constante atualização do acervo bibliográfico da biblioteca do campus.

Apesar do número de bolsas disponíveis não ser suficiente para suprir a demanda estudantil, há uma boa participação dos alunos tanto em eventos dentro do IFCE, inclusive na condição de comissão organizadora, como em encontros e congressos em outras instituições e estados, muitas vezes com o auxílio institucional. Assim, um fator que caracteriza o perfil docente e discente, a nosso ver um potencial para a formação profissional em Serviço Social no IFCE, é que, eventualmente, participam de encontros, congressos e oficinas durante o ano, estando presentes na maioria dos eventos de relevância nacional e regional.

Atualmente, existem 02 núcleos de pesquisa, certificados pelo IFCE e cadastrados no Diretório de Grupos de Pesquisa no Brasil do $\mathrm{CNPq}$, vinculados ao curso, respectivamente denominados: Núcleo de Educação, Políticas Sociais e Serviço Social (NEPSSS) e Núcleo de 
Estudos e Pesquisa Trabalho, Questão Social e Serviço Social (NETRASS). Sobre as atividades de pesquisa, conforme informações da coordenação do curso, de 2012 a 2014, docentes e estudantes desenvolveram em torno de 05 (cinco) projetos, além de mais 03 (três), em andamento no ano de 2015, por intermédio de editais internos do Programa Institucional de Bolsas de Iniciação Científica (PIBIC) do IFCE como também de edital externo do Ministério do Desenvolvimento Social (MDS) e CNPq, totalizando cerca de 14 (quatorze) bolsas de pesquisa, com a participação direta de mais 13 (treze) estudantes voluntários.

Já em relação a extensão, foram desenvolvidos 03 (três) projetos de 2011 a 2014 e mais 01 (um), em andamento no ano de 2015, a partir do Programa de Extensão Universitária (PROEXT) do MEC e da chamada pública junto ao Ministério das Comunicações (MC). As ações envolveram cerca de 35 (trinta e cinco) estudantes com uma ênfase na questão agrária, marca que atravessa o histórico do campus, e nas políticas sociais da região. Destes, 25 (vinte e cinco) bolsistas.

No âmbito das atividades de monitoria acadêmica, presente desde o início do curso através do Programa de Monitoria Acadêmica do IFCE, 11 disciplinas já foram contempladas, sendo atualmente uma média de 5 disciplinas com monitores bolsistas.

Dentre as atividades que fazem parte do calendário anual do curso, está a realização da Semana de Introdução ao Curso, junto com o CASS, no início de cada semestre e da Semana do Serviço Social, organizada por docentes e discentes do curso desde 2011 em razão da comemoração do dia do Assistente Social. Espaço que também ocorre o Fórum Local de Supervisão de Estágio em Serviço Social. Em geral, são eventos realizados com o apoio do CRESS-CE e demais entidades como a ENESSO, coordenação regional.

\subsection{Da Implantação ao Reconhecimento: contexto e sujeitos}

Segundo os gestores e demais servidores entrevistados, as transformações ocorridas na mudança de EAFI para IFCE influenciaram na criação do Curso de Serviço Social. A criação e consolidação do curso é concebida como um "projeto piloto" para se pensar em uma futura expansão não apenas de curso de Serviço Social como também aqueles que mais se aproximam das Ciências Humanos e Sociais. Nesse percurso, alguns aspectos são destacados como centrais, tais como: a grande expansão de cursos de Serviço Social na modalidade EaD e no setor privado no estado, além da forte procura na comunidade e do fato do curso supostamente não exigir muito investimento.

Quanto ao processo de abertura e consolidação do curso, percebemos que foi atravessado por alguns impasses e tensões que, sob muitos aspectos, persistem no cotidiano do curso, refletindo 
nas condições de trabalho e ensino-aprendizagem. Dentre esses aspectos, é notório o confronto crítico a concepções vigentes de educação, de formação profissional e gestão educacional que se torna mais agravante frente a uma realidade institucional com forte hierarquização e com presença ainda bastante marcante da cultura patrimonialista, fragilizando os processos de democratização interna e de autonomia acadêmica.

Há, porém, por parte dos entrevistados, em especial aqueles que compõem a gestão institucional, uma percepção otimista sobre o curso. Para a maioria, o curso é associado a uma forma da instituição "dialogar" melhor com a comunidade, fazendo cumprir a "função social"; ao desenvolvimento de uma postura crítica na formação; a um grande diferencial em relação aos demais cursos ofertados no IFCE, em especial no campus Iguatu; e, consequentemente, a muitos desafios. Por outro lado, os gestores e demais servidores demonstraram, no período de realização das pesquisas (2012-2013), ainda não conhecer a fundo os princípios e objetivos da formação e a lógica curricular do curso.

Outros aspectos presentes nos depoimentos fazem referência a uma suposta incompatibilidade entre o perfil dos estudantes e professores do curso com a estrutura organizativa da instituição, já que o Serviço Social possui uma direção voltada para um perfil questionador, de reivindicação e luta por direitos, desde a formação ao exercício profissional. Sobre isso, ressaltamos o alto nível de participação e envolvimento dos estudantes e professores com as ações no âmbito do curso, inclusive apresentando preocupações com a formação profissional e com uma maior aproximação entre o curso, os profissionais e as políticas públicas da região através de uma ampliação dos fóruns de debates, das atividades no âmbito do estágio supervisionado, entre outras. Nesse sentido, seria um diferencial em relação ao perfil dos professores e estudantes dos cursos predominantemente ofertados no IFCE.

Entretanto, cabe ressaltar que esses impasses pautados por uma relação aparentemente paradoxal entre a "cultura institucional" e o "projeto profissional do Serviço Social", não estão presentes apenas nos IF's, mas na maioria das instituições de formação, como as Universidades e Faculdades. Isso revela, na verdade, um conjunto de contradições que permeiam não apenas o cotidiano institucional, mas a sociedade como um todo, expressas no constante embate e conflitos de ideias, de projetos de formação, de educação e de sociedade fundamentalmente antagônicos.

Essa realidade implica em concebermos a lógica institucional como não engessada, mas dinâmica e passível a mudanças. Hoje, por exemplo, os IF's são pautados em princípios que muito se aproximam daqueles considerados fundamentais no Código de Ética do/a Assistentes Social, como o "compromisso com a justiça social, equidade, cidadania, ética, preservação do meio ambiente, transparência e gestão democrática (...) natureza pública e gratuita do ensino (IFCE, 2008). Nessa relação, existe um debate importante que, a nosso ver, precisa de uma maior atenção 
por parte do Serviço Social no Brasil: a necessária relação entre educação e tecnologia. Isto mesmo que a concepção de formação técnica e/ou tecnológica hegemônica no capitalismo seja de cunho tecnicista, um dos marcos do conservadorismo no Serviço Social, ainda predominante em muitos países. Porém, esse processo não anula as possibilidades de crítica e de "tomada de consciência" exatamente por meio da relação histórica entre educação e trabalho no desenvolvimento das forças produtivas, de tecnologia, em uma perspectiva mais ampla. Marx (apud Manacorda, 2007, p.100) já nos dizia que "sempre se partiu daquilo que a burguesia entende por ensino técnico e, consequentemente, sempre se deu uma interpretação errada”.

Tais ponderações não nos serve para legitimar um suposto "retorno ao passado" na possível viabilidade de uma formação técnica em Serviço Social a partir da sua inserção nos IF's, ao contrário. Como a história é feita pelas circunstâncias de cada época, não pela vontade de cada indivíduo (inclusive daqueles que estão a frente das instituições) ou pelo movimento circular que ameaça constantemente sucessivas repetições, o intuito é proporcionar mais elementos para ampliarmos nossas reflexões em torno da relação entre formação profissional em Serviço Social e os IF's a partir de outras questões que possam nos oferecer uma análise mais dialética e menos limitada a uma concepção linear das relações institucionais, tais como: qual o papel do Serviço Social nessas instituições? Como a inserção do curso em questão pode influenciar na dinâmica institucional, nos projetos de formação e na perspectiva de tecnologia vigente? E vice-versa?

Levando em consideração tais ponderações, observamos que o curso de Serviço Social no IFCE tem sido associado a mudanças, inclusive na dinâmica institucional. Para muitos, o curso vem demandando modificações e contribuirá nos processos que dizem respeito a gestão coletiva e democratização interna, com o fortalecimento dos colegiados, além da construção de novos parâmetros de formação profissional, de pesquisa e extensão. Essa realidade confirma o entendimento de que o curso de Serviço Social no IFCE caminha junto as mudanças recentes no âmbito dos IF's, inclusive em sua cultura institucional, um processo permanentemente atravessado por disputas de rumos e de projetos.

\section{CONSIDERAÇÕES FINAIS}

A realidade demonstra, portanto, um reconhecimento progressivo do curso, que já o mais procurado no campus Iguatu e um dos mais procurados no IFCE, por parte da comunidade como também da instituição através, por exemplo, do incentivo à participação em eventos acadêmicos de docentes e discentes e o fomento a pesquisa, extensão e atividades de apoio ao ensino. Esse aspecto é central no processo de qualificação profissional, especialmente diante de um cenário tão adverso 
para a garantia dos parâmetros de formação em Serviço Social. Tal fato oferece reais possibilidades ao curso de atrair e formar bons profissionais qualificados.

Observamos um empenho em legitimar essa experiência por parte dos docentes, estudantes e gestores do IFCE, já que se trata de uma formação com muitas particularidades cuja referência é fundamentalmente universitária, como também há uma sinalização por parte das próprias entidades do Serviço Social brasileiro desse esforço. Muito embora, no interior da categoria profissional, haja ponderações no que dizem respeito a condição inédita do curso e no que isso poderá repercutir para o Serviço Social no Brasil. A realidade do curso em questão, dessa forma, apesar de inédita, não é simples, envolve um conjunto de mediações que exigem de nós extrapolar da aparência, do cotidiano, do imediatismo. Isso nos remete também a situarmos a realidade analisada no processo, já sinalizado no início do texto, de precarização e mercantilização da educação.

Por outro lado, é importante observar também as contradições geradas no processo de interiorização das instituições e dos cursos públicos que apresenta a possibilidade de incidir sob a dinâmica local e regional, especialmente no âmbito das políticas sociais, da cultura política e dos fluxos migratórios, viabilizando, por um lado, o acesso a um conjunto de estudantes, com um novo perfil que, muitas vezes, se deparam pela primeira vez com a possibilidade do acesso ao direito a educação superior e da vivência político-organizativa no movimento estudantil, demandando, por parte da instituição, melhorias no âmbito da política de assistência estudantil, entre outras; por outro, a atração de docentes concursados e qualificados para o interior do estado que, em geral, motivados por condições adversas e precárias de trabalho, deparam-se com a atuação muitas vezes inicial em organizações de cunho sindical, tal como vem sinalizando as características das greves mais recentes no serviço público. Nessa perspectiva, concordamos com Arcary (2015, p.07-10) quando nos diz o seguinte: "Em um país com escolaridade média ainda muito baixa [...], não parece difícil reconhecer que a interiorização da Rede, e o crescimento da oferta de vagas em diferentes cursos merecem ser avaliados como processos [...] progressivos, ainda que muito insuficientes".

O curso de Serviço Social do IFCE vem, portanto, se consolidando como uma proposta qualificada e compromissada com os princípios ético-formativos indicados pelo Projeto Profissional construído coletivamente pela categoria de assistentes sociais. Reconhecemos os impasses e dificuldades colocadas no cenário institucional e conjuntural para o curso, entretanto, é possível identificar que prevalece a condição de ser o curso um potencial estratégico tanto de ampliação da esfera pública no âmbito educacional e do direito à educação no país, como de contribuição no enfrentamento às formas mercantis, aligeiradas e bem mais precárias de formação profissional.

Tal condição se consolidará ainda mais caso haja continuamente o fortalecimento políticoorganizativo dos profissionais e estudantes, sendo o Curso de Serviço Social do IFCE uma importante experiência que, sem dúvida, contribuirá para ampliar nossas reflexões e ações no 
âmbito da formação profissional, não apenas para o Serviço Social como profissão, mas para o conjunto da classe trabalhadora brasileira.

\section{REFERENCIAS BIBLIOGRÁFICAS}

ALVES, G. Neodesenvolvimentismo e precarização do trabalho no Brasil (parte I), 2013. Disponível em: 〈www.blogdaboitempo.com>. Acesso em: 02.05.2015.

ARCARY, V. Uma nota sobre os Institutos Federais em perspectiva histórica. 2015. Disponível em: <www.blogconvergencia.org/?cat=4>. Acesso em 12.10.2015.

BOITO JR., A. As bases políticas do neodesenvolvimentismo. 2012. Disponível em:< http://eesp.fgv.br/sites/eesp.fgv.br/files/file/Painel\%203\%20-\%20Novo\%20Desenv\%20BR \%20\%20Boito\%20-\%20Bases\%20Pol\%20Neodesenv\%20-\%20PAPER.pdf.>. Acesso em 20.05.2013.

BRASIL. Código de ética do/a Assistente Social. Lei 8.662, de 07 de Junho de 1993 - Dispõe sobre a profissão de Assistente Social e dá outras providências. Brasília: CFESS, 2012.

. Lei 8.662. Dispõe sobre a profissão de Assistente Social e dá outras providências. Brasília, 07 de junho de 1993.

CASTELO, R. O novo desenvolvimentismo e a decadência ideológica do pensamento. In: Revista Serviço Social \& Sociedade, n.112, p.613-636, 2012.

CRESS. Conselho Regional de Serviço Social. Boletim do CRESS 3a Região. Fortaleza. 2014. Disponível em: http://www.calameo.com/read/001289987fe72d3ab8fc1. Acesso em: 16 mai. 2014.

IFCE. Projeto Político-Pedagógico do Curso de Serviço Social. 2010 (Arquivo Interno) . Projeto Político-Pedagógico do Curso de Serviço Social. 2013 (Arquivo Interno)

KOIKE, M. M. Formação profissional em Serviço Social: exigências atuais. In: Serviço Social: direitos sociais e competências profissionais. Brasília: CFESS/ABEPSS, 2009. 
LEHER, R. “Grandes grupos econômicos estão ditando a formação de crianças e jovens brasileiros". (2015). Disponível em: <www.brasildefato.com.br/node/32359>. Acesso em: 02.10.2015.

MANACORDA, M. A. Marx e a pedagogia moderna. Campinas, SP: Ed. Alínea, 2007.

MEC. Ministério da Educação. Relatório de Avaliação Curso Serviço Social IFCE. 2015 (Arquivo Interno)

MOTA, A.E. Serviço Social brasileiro: profissão e área do conhecimento. In: Revista Katálysis. Florianópolis, SC: UFSC, v.16, p. 17-27, 2013.

${ }^{1}$ Doutoranda em Serviço Social na Universidade Federal do Rio de Janeiro (UFRJ). Mestre em Serviço Social pela Universidade Federal de Pernambuco (UFPE).

${ }^{2}$ Doutoranda em Serviço Social na Universidade Federal do Rio de Janeiro - UFRJ. Graduada em Serviço Social pela Universidade Estadual do Ceará (2003) e Mestre em Sociologia pela Universidade Federal do Ceará (2006).

RECEBIDO EM: Setembro de 2015

APROVADO EM: Abril de 2016 